\title{
Peritonitis de causa no intestinal: una rara complicación de nefrectomía laparoscópica
}

\section{Non intestinal peritonitis: A rare complication of laparoscopic nephrectomy}

\section{Sr. Director:}

La nefrectomía laparoscópica se ha transformado en el procedimiento de elección para la remoción de la mayoría de los riñones benignos. Esta técnica se ha desarrollado por vía transperitoneal, retroperitoneal y mano asistida ${ }^{1-3}$.

En aquellos casos en los cuales hay una reacción inflamatoria importante del riñón como ocurre en las pielonefritis xantogranulomatosa o las pielonoefritis crónicas por litiasis, la vía laparoscópica puede ser más dificultosa y con mayor riesgo de presentar complicaciones o necesidad de conversión a cirugía abierta ${ }^{4-6}$.

Dentro de las complicaciones descritas se encuentran las lesiones intestinales y las vasculares, debido a la importante reacción inflamatoria del riñón afectado que no permite un buen plano de disección entre el tejido perirrenal y las estructuras adyacentes ${ }^{7}$.

Otro de los potenciales riesgos de estos riñones es la posibilidad de ruptura durante la disección y el escurrimiento de pus u orina infectada hacia la cavidad peritoneal con el consecuente riesgo de desarrollar una peritonitis o reacción peritoneal. Para evitar esta complicación algunos autores han propuesto la vía retroperitoneal o lumboscopia, sin embargo, debido al espacio de trabajo reducido y en especial a la reacción inflamatoria ya descrita la disección se torna mucho más dificultosa y mayor es la posibilidad de apertura del peritoneo y conversión a cirugía abierta ${ }^{8}$.

Presentamos el caso de un paciente sometido a nefrectomía laparoscópica que desarrolló una peritonitis secundaria a escurrimiento de pus de un riñón con pionefrosis por litiasis.

Paciente de 62 años en tratamiento por hipertensión arterial crónica y con antecedentes de litiasis urinaria recurrente tratada mediante pielolitectomía bilateral abierta.

En controles por dolor lumbar derecho e infecciones urinarias recurrentes, se pesquisa mediante un TAC abdominal una litiasis coraliforme derecha con atrofia del parénquima renal (fig. 1). Se realiza estudio funcional con cintigrama renal con MAG3 que demostró una función del riñón derecho de $5 \%$. Por este motivo se ofrece al paciente realizar una nefrectomía derecha laparoscópica, lo que es aceptado por el paciente después de firmar un consentimiento informado.

La cirugía se llevó acabo de manera estándar por vía transperitoneal, usando coagulación bipolar y óptica de cero grado. La vena y arteria fueron ligadas en forma separada con Hem-o-lock.

Una vez que los vasos del hilio renal fueron controlados y al terminar la disección del polo superior para liberar completamente la pieza, se produjo una perforación del riñón con escurrimiento de una cantidad moderada de pus a la cavidad peritoneal.

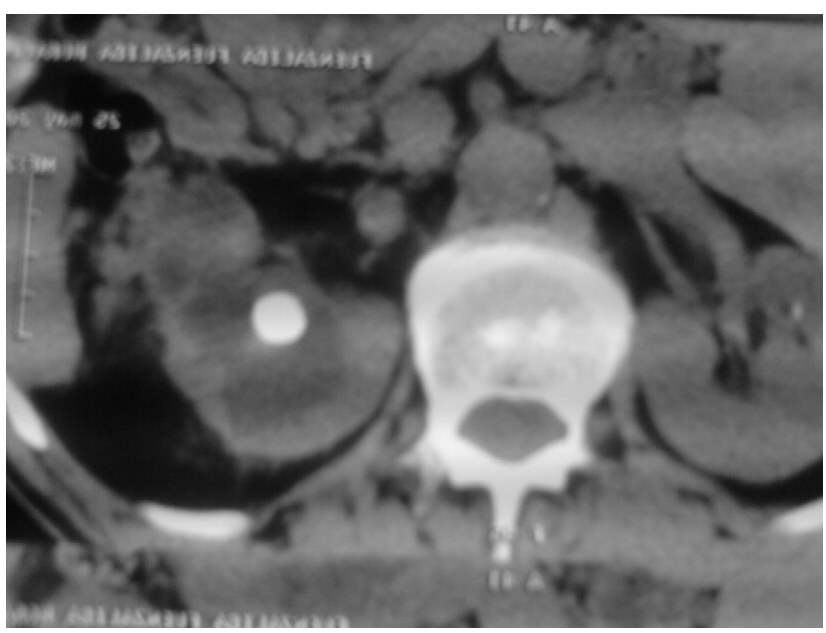

Figura 1 - TAC abdominal que muestra litiasis renal derecha con proceso inflamatorio del parénquima.

El riñón se introdujo en una bolsa plástica y posteriormente se morceló y se retiró por uno de los accesos. Finalmente se realizó aseo de la cavidad peritoneal con abundante cantidad de suero fisiológico.

La cirugía se completó en $140 \mathrm{~min}$ con un sangramiento estimado de 50 cc. No se dejó drenaje abdominal. Se cambió el esquema antibiótico de cefazolina a ceftriaxona.

El paciente evolucionó en forma favorable con dolor abdominal escaso, presentando a las 48 horas post cirugía fiebre de $38^{\circ} \mathrm{C}$. La hemodinamia estaba estable y el abdomen era blando, con dolor leve en zona de heridas con tránsito intestinal presente.

Los exámenes de laboratorio mostraron: hematocrito 37\%, leucocitos 13.600, proteína C reactiva (PCR) $34 \mathrm{mg} / \mathrm{dl}$ y creatinina $1,63 \mathrm{mg} / \mathrm{dl}$.

A las $72 \mathrm{~h}$ el paciente continuaba con fiebre aparecieron vómitos hasta $700 \mathrm{cc}$ y el abdomen estaba distendido, con dolor y resistencia muscular y signos de irritación peritoneal con Blumberg positivo. Los exámenes mostraban: hematocrito $32,8 \%$, leucocitos de 17.200 con desviación a izquierda, creatinina de $3,15 \mathrm{mg} / \mathrm{dl}$ y PCR de $85 \mathrm{mg} / \mathrm{dl}$.

Se realizó un TAC abdominal que demostraba asas distendidas, aire subdiafragmático sin líquido libre ni colecciones abdominales.

El paciente fue llevado a pabellón y se realizó una laparotomía media supraumbilical, donde se encontró las asas intestinales dilatadas, fibrina en moderada cantidad y líquido peritoneal turbio sin mal olor. Se realizó inspección cuidadosa del intestino delgado y colon no encontrando perforaciones. Se realiza aseo 
prolijo de la cavidad con abundante cantidad de suero fisiológico y se deja drenaje tubular.

Se decide aumentar la dosis de ceftriaxona y adicionar metronidazol.

El paciente evoluciona en forma francamente satisfactoria y es dado de alta en buenas condiciones 5 días más tarde, completando una estadía total de 9 días.

La nefrectomía simple laparoscópica para riñones benignos no siempre resulta más fácil que la radical. Esto cobra mayor relevancia cuando se trata de lesiones inflamatorias donde existe una fibrosis del tejido y los planos de disección no son tan claros ni evidentes. En estos pacientes incluso la vía laparoscópica puede ser una vía de acceso controvertida.

Para algunos autores la vía de acceso ideal es la abierta, realizando una gran incisión para poder realizar una disección meticulosa y exenta de complicaciones ${ }^{5}$.

Otro grupo de autores no recomiendan la cirugía laparoscópica para los riñones tuberculosos y con procesos inflamatorios por el mayor riesgo de conversión y de contaminación de la cavidad peritoneal con pus ${ }^{9,10}$.

Así también hay grupos que proponen la nefrectomía laparoscópica. VanderBrink et al compararon una serie de pacientes sometidos a nefrectomía clásica y laparoscópica por pielonefritis xantogranulomatosa, no encontrando diferencias en cuanto a sangramiento, transfusión y analgesia. Los pacientes por vía laparoscópica tenían un menor tiempo de hospitalización ${ }^{11}$.

Es posible utilizar tanto la vía retroperitoneal como la transperitoneal, sin embargo la más usada es la última debido a que existe mayor espacio de trabajo y más estructuras que sirven para la orientación de los cirujanos. Existe un potencial riesgo de infección peritoneal por la orina u otras secreciones contaminadas.

Para prevenir este riesgo, lo ideal es manipular lo menos posible el riñón o grasa perirenal y evitar al máximo una posible rotura o perforación de la pieza. Una de las precauciones es realizar una disección amplia incluyendo la fascia de Gerota para así evitar el contacto directo de los instrumentos con el riñón ${ }^{7}$. Así también en caso de contaminación peritoneal, es posible realizar lavado abundante con suero, sin embargo a veces no es tan fácil debido a que la cánula de aspiración tiende a obstruirse con detritus o se pierde fácilmente el neumoperitoneo.

A medida que nuestro equipo fue aumentando la experiencia en cirugía laparoscópica en general y nefrectomía en particular se fue extendiendo la indicación para estos casos de mayor complejidad ${ }^{12}$. Sin embargo, aunque exista una experiencia adecuada con un buen nivel de habilidad continúa siendo este tipo de intervenciones altamente complejo, demandante y no exento de complicaciones, por lo tanto sugerimos que se debe tener en mente siempre la idea de una conversión a cirugía clásica temprana o utilizar el acceso abierto desde un principio.

B I B L I O G R A F Í A

1. Clayman RV, Kavoussi LR, Soper NJ. Laparoscopic nephrectomy: Initial case report. J Urol. 1991;146:278-82.

2. Kerbl K, Clayman RV, McDougall EM. Transperitoneal nephrectomy for benign disease of the kidney: A comparison of laparoscopic and open surgical techniques. Urology. 1994;43: 607-13.

3. Gill IS. Retroperitoneal laparoscopic nephrectomy. Urol Clin North Am. 1998;25:343-60.

4. Gupta NP, Agarwal AK, Sood S. Tubercular pyelonephritic nonfunctioning kidney: Another relative contraindication for laparoscopic nephrectomy: A case report. J Laparoendosc Adv Surg Tech A. 1997;7:131-4.

5. Bercowsky E, Shalhav AL, Portis A. Is the laparoscopic approach justified in patients with xanthogranulomatous pyelonephritis? Urology. 1999;54:437-43.

6. Shekarriz B, Meng MV, Lu HR. Laparoscopic nephrectomy for inflammatory renal conditions. J Urol. 2001;166: 2091-4.

7. Duarte R, Mitre A, Chambo J. Laparoscopic nephrectomy outside gerota fascia for management of inflammatory kidney. J Endourol. 2008;22:681-6.

8. Khaira H, Shah R, Wolf S. Laparoscopic and open surgical nephrectomy for xantogranulomatous pyelonephritis. J Endourol. 2005;19:813-7.

9. Gupta NP, Agrawal AK, Sood S. Tubercular pyelonephritic nonfunctioning kidney-another relative contraindication for laparoscopic nephrectomy: A case report. J Laparoendosc Adv Surg Tech A. 1997;7:131-4.

10. Keeley FX, Tolley DA. A review of our first 100 cases of laparoscopic nephrectomy: Defining risk factors for complications. Br J Urol. 1998;82:615-8.

11. Vanderbrink BA, Ost MC, Rastinehad A, Anderson A, Badlani GH, Smith $A D$, et al. Laparoscopic versus open radical nephrectomy for xanthogranulomatous pyelonephritis: Contemporary outcomes analysis. J Endourol. 2007;21:65-70.

12. Valero G, Rendic C, Marchant G, González EU. Nefrectomías laparoscópicas: Experiencia inicial de un hospital comunitario. Actas Urol Esp. 2006;30:301-4.

\section{G.R. Valero* y F. Ortiz}

Servicio Urología, Hospital Regional Rancagua, Chile

*Autor para correspondencia.

Correo electrónico: gonzomachali@yahoo.es (G.R. Valero). 